\title{
Morte Progressiva de Ramos de Ficus benjamina Causada por Phomopsis cinerescens nos Estados de Tocantins e Minas Gerais
}

\author{
Milton L. Paz Lima, Carlos H. Uesugi \& Gil R. Santos \\ Universidade de Brasília, Departamento de Fitopatologia, CEP 70910-900, Brasília, DF, e-mail: uesugich@unb.br
}

(Aceito para publicação em 18/05/2004)

Autor para correspondência: Milton L. Paz Lima

\begin{abstract}
First record of dieback of Ficus benjamina caused by Phomopsis cinerescens in the States of Tocantins and Minas Gerais

This is the first recording of twig dieback in Ficus benjamina caused by Phomopsis cinerescens in the States of Tocantins and Minas Gerais, Brazil.
\end{abstract}

O Ficus (Ficus benjamina L.) da família Moraceae é uma planta exótica, originária do continente asiático, usada na extração de resina (goma de benjamin), e produção de incenso. $\mathrm{Na}$ formação de cercas vivas e ornamentação de jardins e interiores é que esta espécie ganha destaque. Nos últimos anos ela vem sendo muito utilizada na arborização de Brasília e outras grandes cidades.

Os sintomas em plantas infetadas são de cancro no tronco que avança para uma seca lateral expansiva de ramos (Figura 1A) devido interrupção da vascularização. Fragmentos de tecido de ramos infetados de ficus coletados no ano de 2003 em Gurupi, TO, e Uberlândia, MG, foram submetidos à assepsia e, em seguida, colocados em meio de cultura BDA, onde desenvolveu um fungo com micélio branco a pardo-escuro e septado, que em meio de cultura formou corpos de frutificação picnidiais que exsudaram longos cirros. Em lâminas semi permanentes dos picnídios visualisaram-se conídios dimórficos, do tipo alfa 8,57-3,94 (6,95) x 4,46-1,71 $(2,65) \mu \mathrm{m}$ (Figura 1B b1), que são geralmente elipsóides, muitas vezes unigutulados; e do tipo beta 23,14-13,45 (21,79) x 1,63-0,60 (0,91) $\mu \mathrm{m}$ (Figura $1 \mathrm{~B}$ - b2) que possuem formatos filiformes, curvados, não gutulados. Alguns picnídios apresentaram apenas conídios beta e outros conídios alfa, e/ou os dois tipos simultaneamente, variação ocorre devido a idade da cultura.

O teste de patogenecidade foi realizado em casa de vegetação, utilizando-se ramos de mudas de fícus, de aproximadamente $50 \mathrm{~cm}$ de altura, depositando discos de $3 \mathrm{~mm}$ de diâmetro contendo meio de cultura e crescimento micelial sobre ferimentos, com aproximadamente $5 \mathrm{~mm}$ de comprimento, feitos nas axilas dos ramos. Plantas inoculadas com meio BDA serviram de controle. Sete a dez dias após, verificou-se o aparecimento dos primeiros sintomas de morte ascendente dos ramos, culminando com a morte dos ramos afetados, de igual semelhança ao encontrado naturalmente em arborização urbana. Todas as plantas inoculadas apresentaram sintoma de morte dos ramos. Dos ramos com sintomas, re-isolou-se o mesmo fungo, completando os postulados de Koch. Estudos morfológicos e morfométricos permitiram identificar o agente causal da morte progressiva de ficus como sendo Phomopsis cinerescens (Sacc.) Trav. (Grove, W.B. 1935, British stem and leaf fungi, vol.1, Cambridge University Press; Benschop et al. Canadian Plant Disease Survey, 64(2): 29-31. 1984), sendo este o primeiro registro de ocorrência da doença no Brasil.

Danos causados por $P$. cinerescens Trav. em ficus foram registrados nos Estados Unidos (Conover \& Poole, Horticulture Science 102:529. 1977; Hudler, Flower Industries Bulletin 104:10. 1979 e Anderson \& Hartman, Foliage Digest 6:5. 1983), e no Canadá, Benschop et al. (Canadian Plant Disease Survey 64:29. 1984), confirmando a gravidade e a importância da doença para a cultura. Viégas (Índice de Fungos da América do Sul, ed. Inst Agronômico, SP/SP, 1961) relatou a ocorrência de $P$. cinerescens em figo ( $F$. caricae L.), sendo este considerado o hospedeiro mais citado em literatura (Lentz \& Weaver, Plant Dis.Rep. 39:822. 1955).

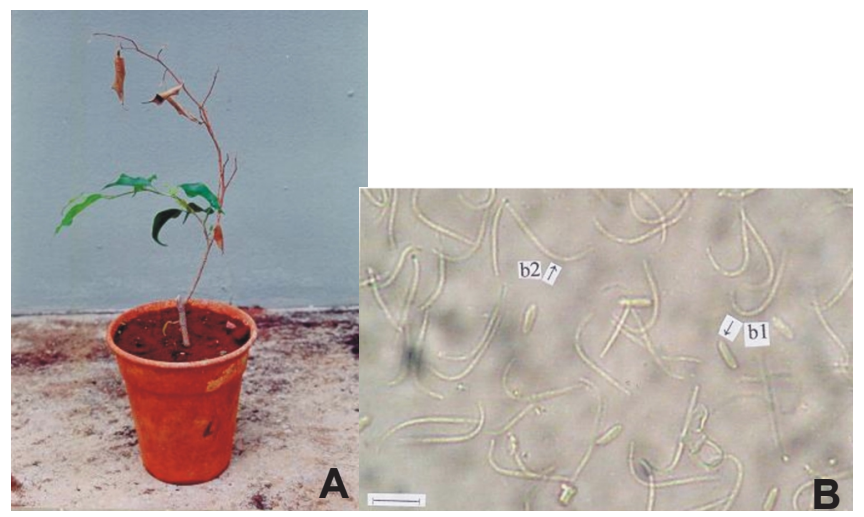

FIG. 1 - Ficus benjamina infetado por Phomopsis cinerescens. A. sintoma de seca de ramos em muda; B. conídios alfa (b1) e beta (b2) (barra=10 $\mu \mathrm{m})$. 